Article

\title{
Particulate Matter and Its Impact on Mortality among Elderly Residents of Seoul, South Korea
}

\author{
Satbyul Estella Kim ${ }^{1, *}$, Yasuaki Hijioka ${ }^{1}$, Tatsuya Nagashima ${ }^{2}$ and Ho Kim ${ }^{3}$ (D) \\ 1 Center for Climate Change Adaptation and Center for Social and Environmental Systems Research, National \\ Institute for Environmental Studies, Tsukuba 305-8506, Japan; hijioka@nies.go.jp \\ 2 Center for Regional Environmental Research, Regional Atmospheric Modeling Section, National Institute for \\ Environmental Studies, Tsukuba 305-8506, Japan; nagashima.tatsuya@nies.go.jp \\ 3 Department of Health Sciences, Graduate School of Public Health, Seoul National University, Seoul 08826, \\ Korea; hokim@snu.ac.kr \\ * Correspondence: kim.satbyul@nies.go.jp
}

Received: 14 November 2019; Accepted: 19 December 2019; Published: 23 December 2019

check for updates

\begin{abstract}
Climate change, air pollution, and the rapidly aging population are important public health challenges. An understanding of air pollution impacts is imperative for preventing air-pollution-related deaths and illnesses, particularly in vulnerable subgroups such as the increasing population of older adults. To assess the effects of short-term air-pollution exposure on the elderly, we conducted a time-series analysis (1996-2015) of the associations between particulate matter with an aerodynamic diameter of $<10 \mu \mathrm{m}\left(\mathrm{PM}_{10}\right)$ and deaths among elderly residents of Seoul, South Korea, which has a rapidly aging population. We also investigated the synergistic effects of temperature and the lag structures of the effects by sex, cause of death, and season. A $10 \mu \mathrm{g} / \mathrm{m}^{3}$ rise in the 4-day moving average concentration of $\mathrm{PM}_{10}$ was associated with $0.31 \%$ (95\% confidence interval (CI): $0.18 \%$ to $0.44 \%$ ), $0.32 \%$ (95\% CI: $0.09 \%$ to $0.55 \%$ ), and $0.22 \%$ (95\% CI: $-0.23 \%$ to $0.66 \%$ ) increases in non-accidental, cardiovascular, and respiratory mortalities, respectively. We found a significant and strong synergistic effect of $\mathrm{PM}_{10}$ concentration and ambient temperature on mortality in elderly people. $\mathrm{PM}_{10}$ posed an increased risk of non-accidental or cardiovascular mortality with increasing temperature, whereas the associated risk of respiratory death was highest on very cold days. The shape and length of the lag structure varied with the cause of death, sex, and season. Results indicate that elderly people exposed to $\mathrm{PM}_{10}$ are at increased risk of premature death. In the near future, these risks are likely to increase in step with the temperature rise associated with climate change and the continued population aging. Stronger emission controls will be needed to minimize the increased health risks associated with air pollution, especially in regions with high populations of elderly individuals.
\end{abstract}

Keywords: air pollution; particulate matter; health impact; elderly mortality; South Korea

\section{Introduction}

Air quality and its impact on health are major environmental health issues [1]. In particular, the high concentration of particulate matter (PM) is a rising socioenvironmental issue in South Korea owing to its large impacts on the health and lifestyle of residents [2]. It has been suggested that short-term exposure to PM affects vulnerable subpopulations, such as the elderly, who are at elevated risk of dying owing to their poor health $[3,4]$. Because aging is associated with declines in adaptive and innate immunity, as well as with comorbidities, exposure to PM may be fatal in elderly individuals $[5,6]$. In the last four decades, South Korea has shown the most extreme demographic shift among advanced economies, with its population aging at the fastest pace [7]. Most previous air-pollution-related health 
impact studies in South Korea have reported on risks to the whole population, or in elderly people compared with the rest of the population, instead of focusing solely on the elderly population [8]. Furthermore, to our knowledge, the synergistic effect of air pollution and ambient temperature on mortality in the South Korean elderly population has not been fully evaluated. Recent studies in different populations have suggested that air pollution and temperature may act jointly-the effects of pollutants may be modified because of residual confounding by temperature [9-12]. Given the rapid expansion of the older population, the interactive effect of PM and temperature among elderly individuals is of public health concern. The increasing temperatures associated with climate change have the potential to adversely and disproportionately affect older people. A further issue is the length of the lag period (delay). The time between initial exposure to a pollutant and various health outcomes depends on how the pollutant interacts with a target organ, and this interaction can lead to a specific disease [13].

Here, we investigated the association between increases in ambient PM concentrations and the subsequent risk of mortality among elderly residents of Seoul, South Korea, by using flexible modeling strategies with adjustment for an array of potential confounders. We also assessed the joint effects of temperature, and the lag structures of the effects by cause of death, sex, and season.

\section{Materials and Methods}

\subsection{Study Location}

The study was conducted in Seoul $\left(37.34^{\circ} \mathrm{N}, 126.59^{\circ} \mathrm{E}\right)$, which is the capital of one of the fastest-aging developed countries, South Korea (Figure 1). The population density of Seoul is high $\left(16,364\right.$ persons $\left./ \mathrm{km}^{2}\right)$, with approximately 10 million people living in a land area of $605.25 \mathrm{~km}^{2}$. This is only $0.6 \%$ of the total area of South Korea, but is home to one-fifth of the country's residents [14]. The aging rate (the proportion of a society's population that is composed of people older than 64 years) of Seoul was 15\% (as of September 2019) [15]. There is increasing concern about PM problems in Seoul. The annual mean concentration of PM with an aerodynamic diameter of $<10 \mu \mathrm{m}\left(\mathrm{PM}_{10}\right)$ in Seoul $\left(44 \mu \mathrm{g} / \mathrm{m}^{3}\right.$ in 2017) is far higher than the air quality guidelines of the World Health Organization $\left(20 \mu \mathrm{g} / \mathrm{m}^{3}\right)$ [16]. Given the high population density, high aging rate, and PM issue, Seoul is a suitable city for assessing the health impacts of urban air pollution in the elderly.

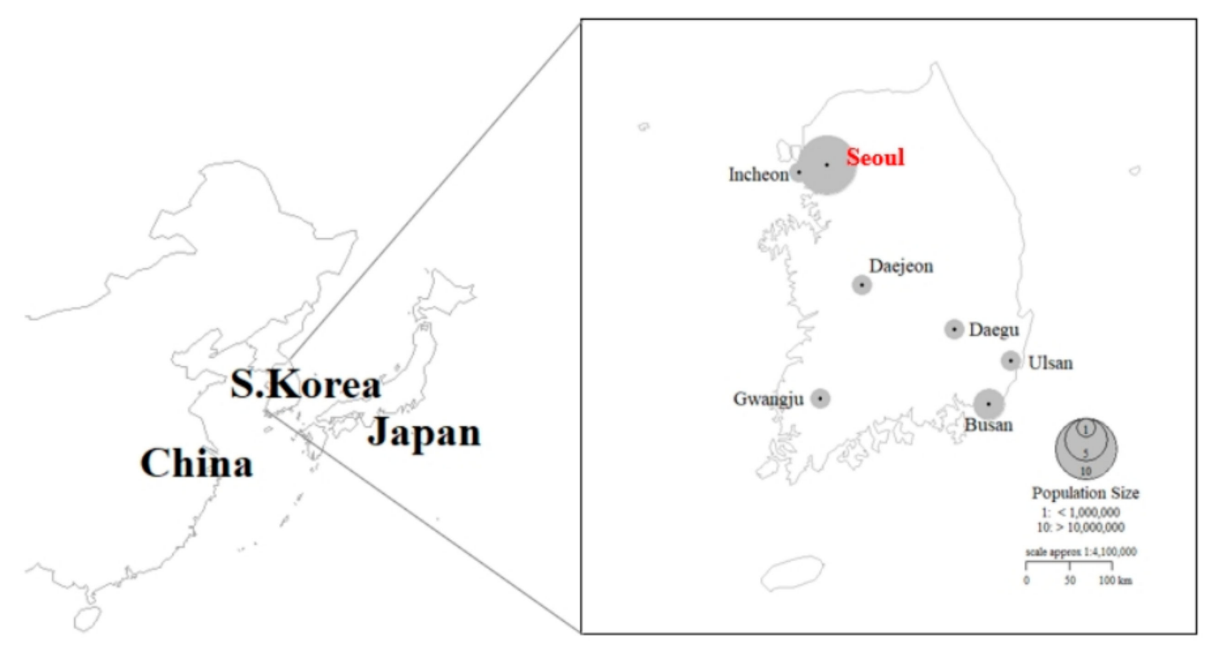

Figure 1. Study location, Seoul, South Korea.

\subsection{Data}

The analysis included deaths that had occurred among elderly residents ( $\geq 65$ years) in Seoul between 1 January 1995 and 31 December 2014. Daily numbers of deaths from the mortality data provided by Statistics Korea were classified according to the International Classification of 
Diseases, 10th Revision (ICD-10) as non-accidental causes (ICD-10: A00-R99), cardiovascular causes (ICD-10: I00-I52), and respiratory causes (ICD-10: J00-J98). Meteorological data on 24-h mean temperatures $\left({ }^{\circ} \mathrm{C}\right)$, relative humidity $(\%)$, and atmospheric pressure $(\mathrm{hPa})$ were obtained from the Korean Meteorological Administration (KMA). The 24-h average concentration of $\mathrm{PM}_{10}$, provided by the Ministry of the Environment, Republic of Korea (KMOE), was used as the daily exposure index. Hourly mean concentrations across the monitoring stations were calculated by averaging monitor-specific concentrations. The daily representative concentrations of $\mathrm{PM}_{10}$ were then calculated by averaging the 24 -h values. The number of monitoring stations scattered throughout Seoul increased from 20 in 1995 to 25 in 2014; this is discussed further in the limitations section.

\subsection{Statistical Analyses}

We conducted a time-series analysis by using a generalized additive model to explore the impacts of $\mathrm{PM}_{10}$ on premature death in elderly individuals. A Poisson distribution with overdispersion was assumed. Possible confounding factors that might have influenced the relationship between $\mathrm{PM}_{10}$ and death counts, such as long-term trend fluctuations, seasonality, relative humidity, day-of-the-week effect, and temperature, were controlled for. Potential nonlinear effects of confounding factors were modeled using smoothing functions with a cubic spline basis, defined by a set of knots spread evenly through the covariate values, with the conventional integrated-square second-derivative penalty [17].

$$
\begin{aligned}
& Y_{t} \sim \text { quasi-Poisson }\left(\mu_{t}\right) \\
& \ln \left(\mu_{t}\right)=\beta_{0}+\beta_{1}\left(\text { PM }_{10 t-i}\right)+s\left(\text { Temperature }_{t-i}, d f\right)+\text { DOW }_{t} \\
& +s(\text { Relative humidity, } d f)+s(\text { Air pressure }, d f)+s\left(\text { Time }_{t}, d f\right) \text {, }
\end{aligned}
$$

where $Y_{t}$ refers to the mortality count on day $t, \mu_{t}$ is the expected mortality count on day $t, i$ is the lag; and $D O W$ is a categorical variable for the day of the week on day $t . s($.) denotes the smoothing function realized by using cubic spline bases, with three degrees of freedom (df) for temperature, four $\mathrm{df}$ for relative humidity and air pressure, and seven $\mathrm{df}$ per year for time to adjust for seasonal and long-term trends, as based on a previous environmental epidemiologic study conducted in South Korea [18]. To investigate the interactive effect of $\mathrm{PM}_{10}$ and temperature on mortality, we stratified the effect of $\mathrm{PM}_{10}$ on each health outcome by the percentile of the mean temperature $(<1$ st, 1 st to $<5$ th, 5 th to $<25$ th, 25 th to $<75$ th, 75 th to $<95$ th, 95th to $<99$ th, and $\geq 99$ th percentiles). This approach provided a numerical comparison of the effects of $\mathrm{PM}_{10}$ on mortality in the different temperature strata, while allowing for heterogeneity of the effects of $\mathrm{PM}_{10}$ across the strata [11]. Furthermore, we examined the effects of $\mathrm{PM}_{10}$ under different lag structures, because a delayed health effect is known to exist in the association between $\mathrm{PM}_{10}$ and mortality [13]. Specifically, we explored the lag structures of $\mathrm{PM}_{10}$ in elderly people during the warm months (April to September) and the cold months (October to March) by cause of death and sex. The lags of $\mathrm{PM}_{10}$ included lag 0 , the present (single) day, and multiday lags [MA0-1 (the 2-day moving average of the present day and the previous day) up to MA14 (the 15-day moving average of the present and previous 14 days)], because single-day lag models underestimate the cumulative health effects of air pollution [19]. All lags were reported and, based on previous studies [20-22], the lag showing the strongest effect estimates (MA03) was selected from among the lag structures to present the main results. We calculated the relative risk of mortality for a $10-\mu \mathrm{g} / \mathrm{m}^{3}$ increase in $\mathrm{PM}_{10}$ concentration, and all results are presented as percent increase in mortality, with the corresponding 95\% confidence interval (CI). All analyses were performed with the statistical software R version 3.6.1 (R Foundation for Statistical Computing, Vienna, Austria).

\section{Results}

Table 1 summarizes the daily mortality data of the elderly population in Seoul during the study period by cause of death, sex, and season. The study included a total of 457,963 non-accidental deaths (average, 62.69 deaths/day), with 29\% from cardiovascular disease and 8\% from respiratory disease. 
The rate in females was 33.94 deaths/day and in males 28.75 deaths/day. The average number of deaths per day was greater during the cold months (mean $=66.04, \mathrm{SD}=12.20$ ) than in the warm months (mean $=59.36, \mathrm{SD}=11.60)$. A time-series plot of $\mathrm{PM}_{10}$ concentrations in Seoul during the study period (Figure 2) revealed a significant decrease. Overall, the average mass concentration of $\mathrm{PM}_{10}$ in the study period was $60.35 \mu \mathrm{g} / \mathrm{m}^{3}$. This value was relatively high during spring $\left(73.56 \mu \mathrm{g} / \mathrm{m}^{3}\right)$ and winter $\left(66.38 \mu \mathrm{g} / \mathrm{m}^{3}\right)$ and relatively low during summer $\left(48.93 \mu \mathrm{g} / \mathrm{m}^{3}\right)$ and autumn $\left(52.58 \mu \mathrm{g} / \mathrm{m}^{3}\right)$. When the data were sorted into warm and cold months, the average $\mathrm{PM}_{10}$ concentration was higher in the cold months $\left(65.25 \mu \mathrm{g} / \mathrm{m}^{3}\right)$ than in the warm months $\left(55.48 \mu \mathrm{g} / \mathrm{m}^{3}\right)$.

Table 1. Summary statistics of daily mortality of elderly ( $\geq 65$ years) by cause of death, sex, and season in Seoul, South Korea (1994-2014).

\begin{tabular}{cccccc}
\hline Category & Sub-Category & Mean & SD & Min & Max \\
\hline \multirow{3}{*}{ Cause of Death } & NAD & 62.69 & 12.11 & 28 & 114 \\
& CVD & 17.68 & 4.7 & 4 & 37 \\
& RD & 5.10 & 2.72 & 0 & 18 \\
\hline \multirow{2}{*}{ Sex } & Male & 28.75 & 7.96 & 7 & 65 \\
& Female & 33.94 & 6.98 & 13 & 64 \\
\hline \multirow{2}{*}{ Season ${ }^{1}$} & Warm & 59.36 & 11.06 & 28 & 103 \\
& Cold & 66.04 & 12.20 & 32 & 114 \\
\hline
\end{tabular}

1 Seasons were classified into warm months (April to September) and cold months (October to March). NAD, non-accidental death; $C V D$, cardiovascular disease; $\mathrm{RD}$, respiratory disease.

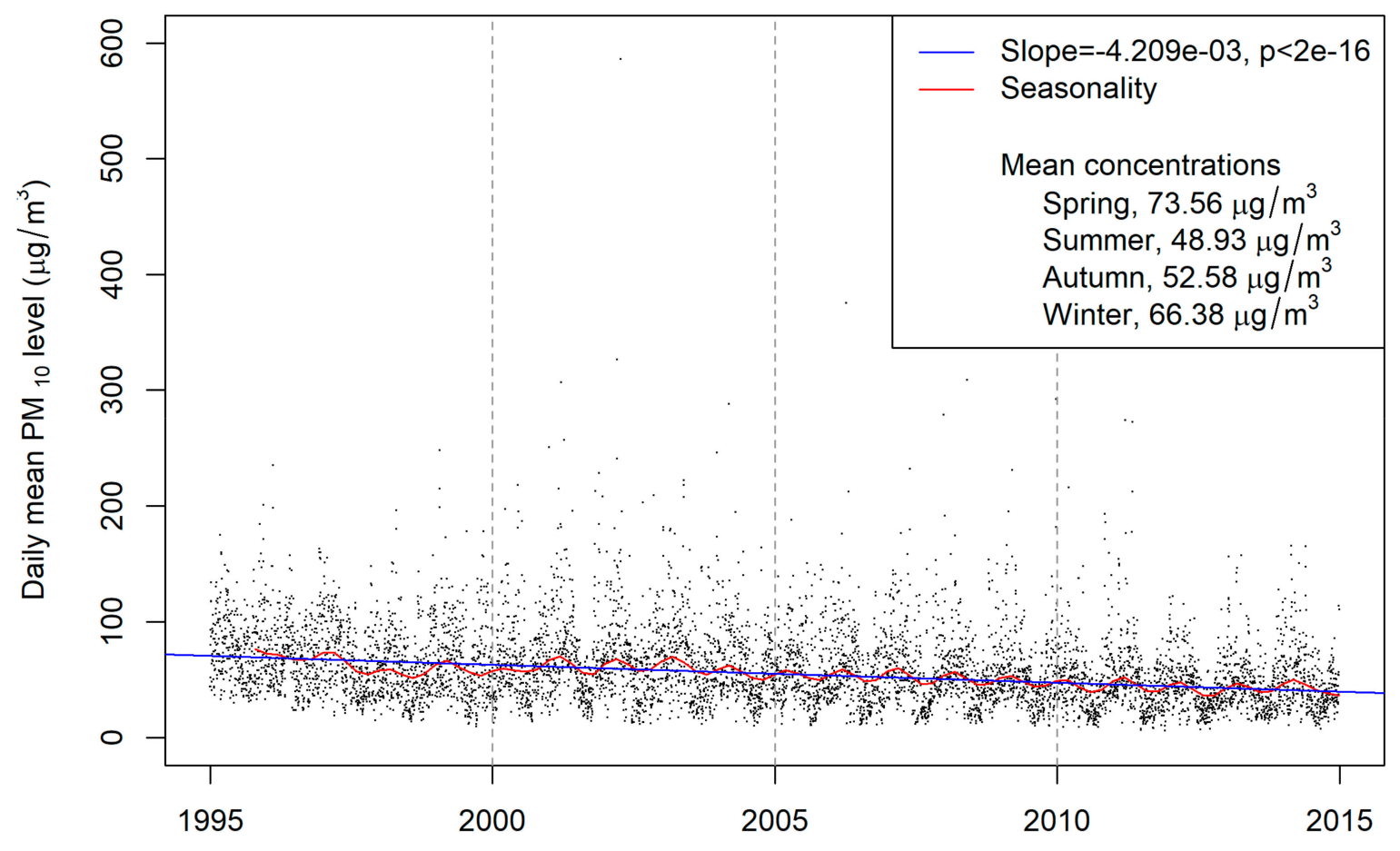

Figure 2. Time-series plot of daily mean particulate matter with an aerodynamic diameter of $<10 \mu \mathrm{m}$ $\left(\mathrm{PM}_{10}\right)$ concentrations in Seoul between 1 January 1995 and 31 December 2014.

We plotted the overall percentage increases (mean and CI) in cause-specific mortality associated with a $10 \mu \mathrm{g} / \mathrm{m}^{3}$ increase in $\mathrm{PM}_{10}$ at MA03 (the moving average for the current day and the previous 3 days) among the elderly in Seoul during the study period (Figure 3). We observed positive associations between mortality and $\mathrm{PM}_{10}$ at MA03. The associations were significant for non-accidental death ( $0.31 \%$ increase; $95 \%$ CI: $0.18 \%$ to $0.44 \%$ ) and cardiovascular disease mortality $(0.32 \%$; $95 \%$ CI: $0.09 \%$ to $0.55 \%)$, but not for respiratory disease mortality $(0.22 \% ; 95 \% \mathrm{CI}:-0.23 \%$ to $0.66 \%)$. In all three disease 
categories the risks of death were greater, but not statistically significant, in males compared to females $(P>0.05)$.

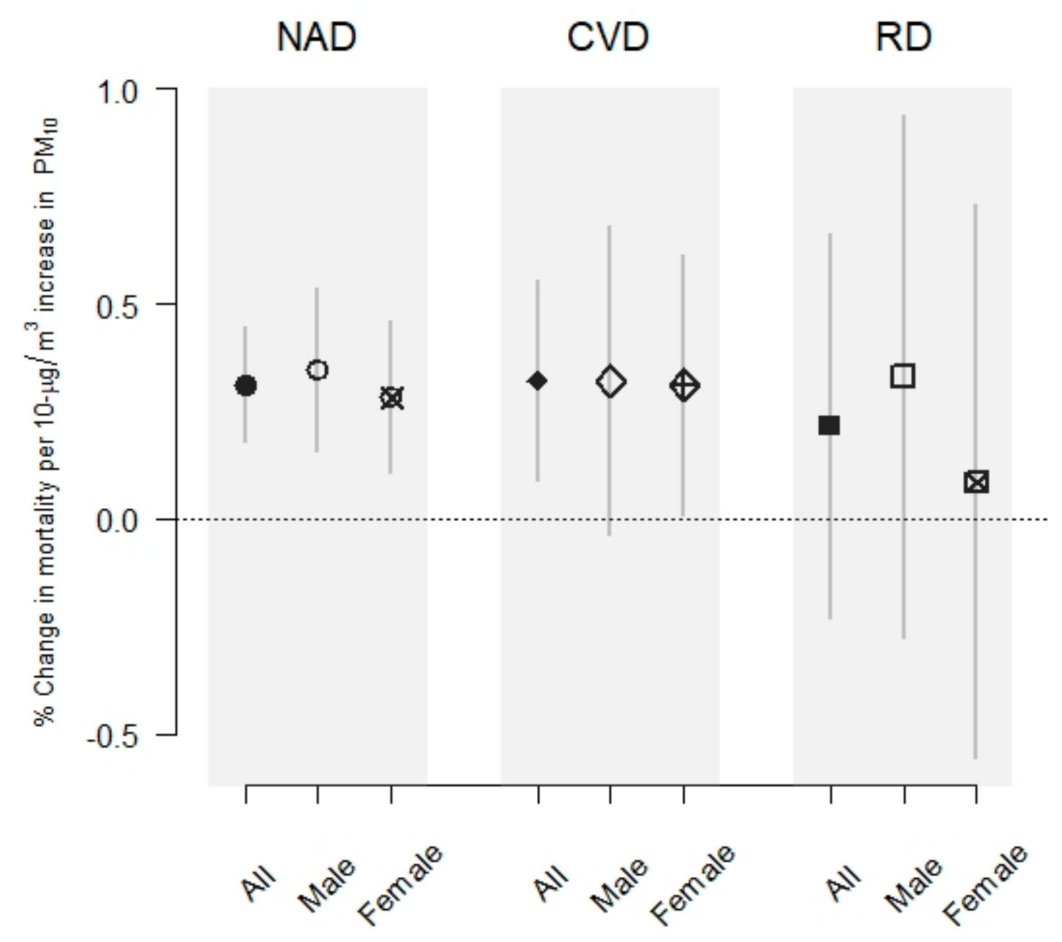

Figure 3. Percent changes in non-accidental death (NAD), cardiovascular disease (CVD), and respiratory disease (RD) mortalities in elderly Seoul residents, with a 95\% confidence interval, for a $10 \mu \mathrm{g} / \mathrm{m}^{3}$ increment in $\mathrm{PM}_{10}$ at MA03 (the moving average for the current day and the previous 3 days).

We plotted the risks associated with a $10 \mu \mathrm{g} / \mathrm{m}^{3}$ increment in $\mathrm{PM}_{10}$ in terms of non-accidental death and mortalities from cardiovascular and respiratory disease, stratified by temperature $(<1$ st, 1 st to $<5$ th, 5 th to $<25$ th, 25th to $<75$ th, 75th to $<95$ th, 95th to $<99$ th, and $\geq 99$ th percentiles) (Figure 4). Associated with this $\mathrm{PM}_{10}$ increment was an increasing trend in the risk of non-accidental death and cardiovascular disease mortality as the temperature increased. In these stratification models, an increase of $10 \mu \mathrm{g} / \mathrm{m}^{3}$ in $\mathrm{PM}_{10}$ was significantly associated with a $3.02 \%$ (95\% CI: $2.29 \%$ to $3.75 \%$ ) increase in non-accidental death and a $3.05 \%$ (95\% CI: $1.76 \%$ to $4.36 \%$ ) increase in cardiovascular mortality on very hot days ( $\geq 99$ th percentile). On the other hand, the risk of death from respiratory disease was the highest, and significant $(2.02 \%$; $95 \%$ CI: $0.22 \%$ to $3.86 \%)$, on very cold days ( $<1$ st percentile).

We then plotted a number of lag structures (Figure 5). Overall, lags in respiratory disease mortality persisted longer than those in cardiovascular disease mortality. Lags in non-accidental death and cardiovascular disease mortality were longer during the cold months than during the warm months. In females, there were longer lags than in males in all three categories of mortality during the warm months. On the other hand, in males there were longer lags than in females during the cold months. 
(a) NAD
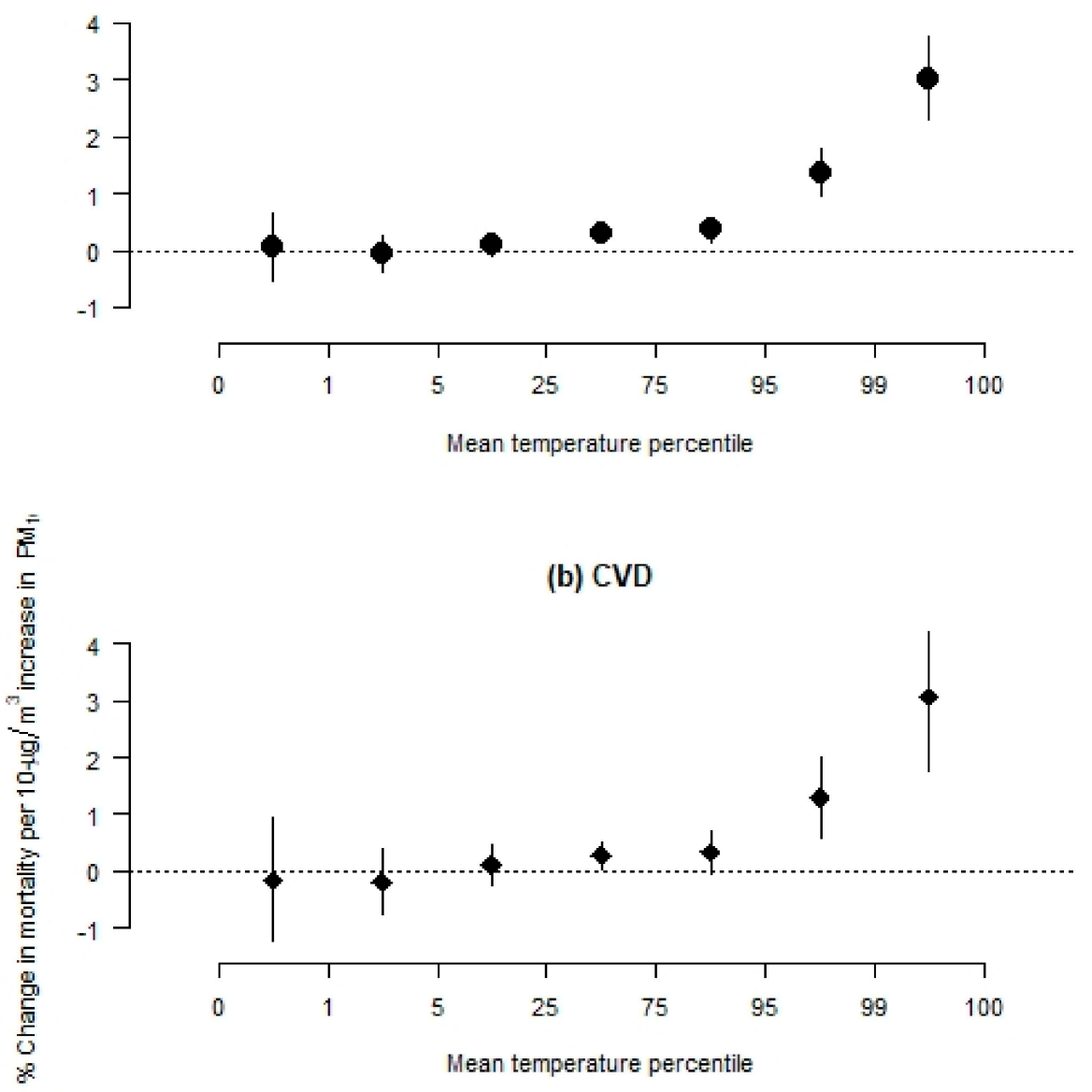

(c) RD

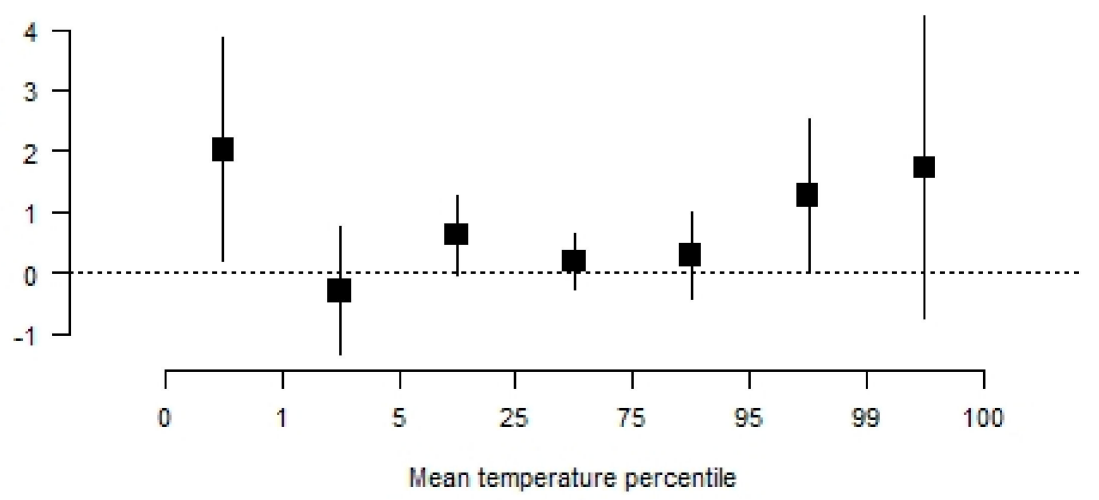

Figure 4. Percent changes in (a) non-accidental death (NAD), (b) cardiovascular disease (CVD) mortality, and (c) respiratory disease (RD) mortality in elderly Seoul residents, with a 95\% confidence interval, for a $10 \mu \mathrm{g} / \mathrm{m}^{3}$ increment in $\mathrm{PM}_{10}$, by daily mean temperature percentile ( $<1 \mathrm{st}, 1 \mathrm{st}$ to $<5$ th, 5 th to $<25$ th, 25 th to $<75$ th, 75 th to $<95$ th, 95th to $<99$ th, and $\geq 99$ th percentiles) at MA03 (the moving average for the current day and the previous 3 days). 


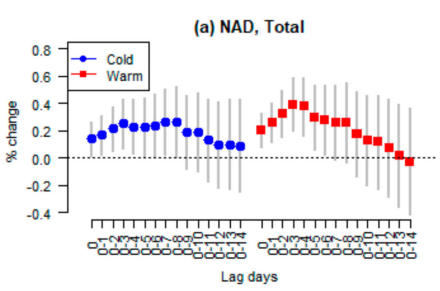

(d) NAD, Male

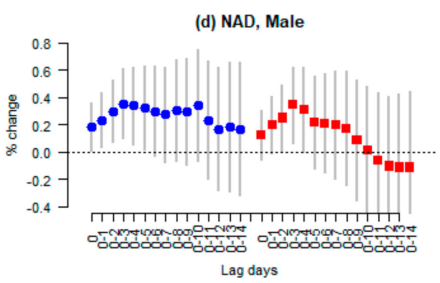

g) NAD, Female

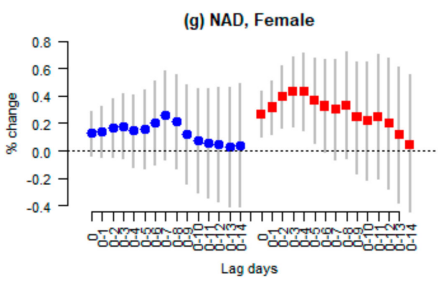

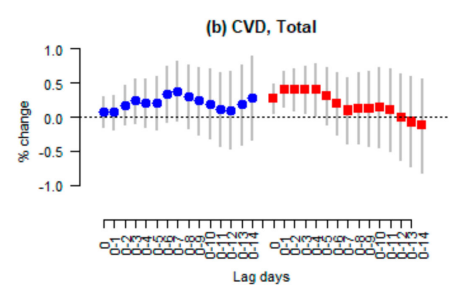

Lag days
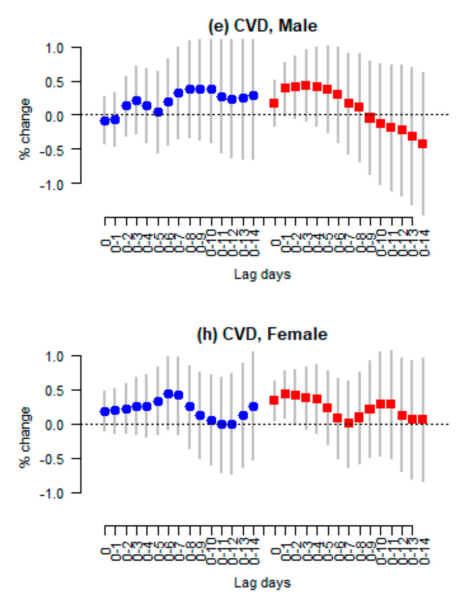
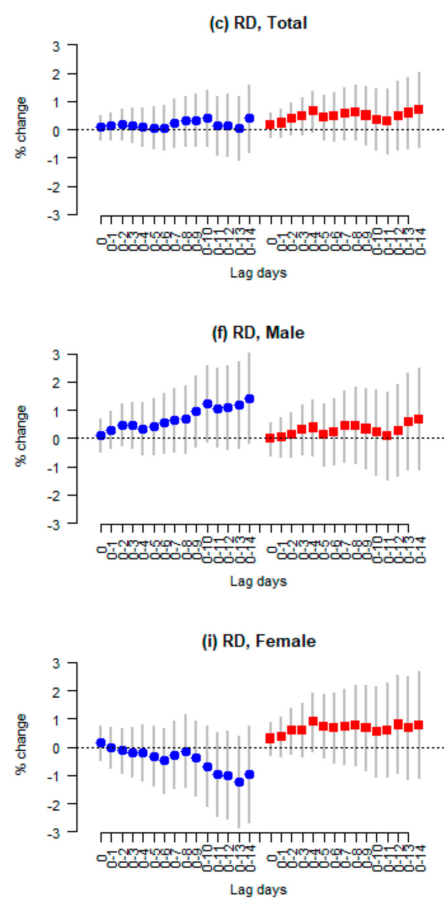

Figure 5. Lag structures of the effects of a $10 \mu \mathrm{g} / \mathrm{m}^{3}$ increase in $\mathrm{PM}_{10}$ on mortality in elderly Seoul residents, by disease category, sex, and season. Seasons were classified into warm months (April to September) and cold months (October to March). (a) non-accidental mortality, total; (b) cardiovascular disease mortality, total; (c) respiratory disease mortality, total; (d) non-accidental mortality, male; (e) cardiovascular disease mortality, male; (f) respiratory disease mortality, male; (g) non-accidental mortality, female; (h) cardiovascular disease mortality, female; (i) respiratory disease mortality, female.

\section{Discussion}

We found here that $\mathrm{PM}_{10}$ was positively associated with increases in non-accidental, cardiovascular, and respiratory disease mortalities in elderly residents of Seoul, South Korea, with differences in the magnitude and significance of the risk. Our estimates are slightly higher than those reported in China $(0.26 \%$; $95 \%$ CI: $0.15 \%$ to $0.38 \%)$ for total mortality in the elderly [23], but they are lower than the risks estimated in the tropics by using distributed lag models (lags 0 to 5 ) for non-accidental $(0.77 \%$; 95\% CI: $0.27 \%$ to $1.23 \%$ ) and cardiovascular (1.24\%; $95 \%$ CI: $0.44 \%$ to $2.04 \%$ ) mortalities in elderly individuals [24].

Recent studies have addressed the issue of synergy between temperature and pollution, and the resulting effects on health [9-12]. Therefore, we further estimated these synergistic effects and observed significant synergism in the effects of temperature and $\mathrm{PM}_{10}$ concentration on mortality in elderly people. For non-accidental and cardiovascular causes of death, the risk increased significantly on days with increased ambient temperature. A similar finding was observed by Tian et al. [12] in their study in Beijing, China. However, in pooled estimates from seven cities in South Korea between 2000 and 2009, the effects of $\mathrm{PM}_{10}$ on non-accidental and cardiovascular mortalities in the elderly were highest in the temperature range of the 95th to 99th percentile, not the 99th to 100th percentile as we found here [11]. The likely differences among locations in demographic, economic, and other characteristics of air pollution levels and temperature contribute to differences in the interactive effects between $\mathrm{PM}_{10}$ and temperature. Although many other investigations of the interaction between air pollution and temperature have focused on hot weather rather than cold weather [9], we found that respiratory mortality risk in the elderly was highest on very cold days $(<1$ st percentile). In winter, Seoul usually has poor air quality owing to a combination of local climatic conditions and domestic and transboundary anthropogenic emissions [25]. Although we found here that non-accidental and cardiovascular mortality risks increased during the warm months, attention to the effects of pollution 
is needed not only during this time of year, when the known risk is higher, but also during the cold months, when the concentration of $\mathrm{PM}_{10}$ is higher than in warm months.

Lag structures in the relationship between PM concentration and health outcomes have been previously assessed $[13,22,26]$. In our assessment of the lag effects of $\mathrm{PM}_{10}$ on cause-specific mortality, we found that the short-term effects of a rise in $\mathrm{PM}_{10}$ concentration on mortality persisted for longer periods in the case of respiratory mortality than in the case of cardiovascular mortality. In particular, during the warm months, the effects of an increase in $\mathrm{PM}_{10}$ concentration on daily deaths persisted over two weeks for respiratory disease, whereas the effects persisted for only one week for cardiovascular mortality. Similar findings have been observed in studies of 10 European cities [26] and 20 US cities [22]. This can be explained partly by biological mechanisms related to the cardiovascular and respiratory effects of exposure to PM. Cardiovascular events can be triggered immediately in response to autonomic stimulation of the cardiovascular system, whereas the exacerbation of respiratory disease takes longer because of the time taken for airway damage and inflammation to develop [27-29]. A clear seasonal modification of the effects of $\mathrm{PM}_{10}$ was also evident. As Zeka et al. [22] also observed, we found a greater effect of an increase in $\mathrm{PM}_{10}$ concentration on mortality in the warm months than in the cold months. Furthermore, in the case of non-accidental and cardiovascular deaths, the lag was shorter (i.e., the effect was more immediate) during the warm months than in the cold months. We also observed different lag patterns of mortality risk in relation to sex. The lag effect was longer in females than in males during the warm months, whereas the opposite applied during the cold months. This could be a phenomenon due to differential exposure (e.g., work-related co-exposures) as well as biological differences by sex (e.g., hormonal status) [30]. Our findings add to the previous literature, because they confirm that lag structures vary depending on cause of death, sex, and season. These different patterns of lag effects for different disease outcomes, sex, and season may provide insight into the different biological mechanisms of PM [13].

An aging society is defined by the United Nations as a society in which the share of the population aged 65 and over exceeds $7 \%$ of the total population; an aged society is one where this share exceeds $14 \%$ of the total population. It took only 17 years for South Korea to transition from an aging society $(7.2 \%$ in 2000$)$ to an aged society $(14.3 \%$ in 2018 , whereas it took 115 years in the case of France [31]. Furthermore, by 2025 South Korea is expected to become a super-aged society, at 20.1\% [32]. Given this upcoming demographic reality in South Korea, an effective prevention strategy is needed to keep the elderly population healthy in the face of outdoor air pollution. Although effective policies to reduce emissions are obviously desirable, individual actions might also be effective in reducing exposure and health risks [33]. Personal exposure to ambient air pollution could be reduced by wearing a mask on high-air-pollution days. However, in the case of elderly people with cardiovascular or respiratory diseases this might disrupt the inhalation of sufficient oxygen. Therefore, it is important to develop and promote scientific-evidence-based specific behavioral guidelines for the elderly that can be applied in real life.

Finally, some limitations of the study need to be mentioned. First, we used $\mathrm{PM}_{10}$ data collected across 20 years from 1995 to 2014 . However, the concentrations in the early years might have been less precise than those in the later years-the precision of the data might have been improved because the number of individual sampling stations increased over time [34]. Second, we used $\mathrm{PM}_{10}$ data because they covered more years than the available $\mathrm{PM}_{2.5}$ (particulate matter $\leq 2.5 \mu \mathrm{m}$ in aerodynamic diameter) data. Official statistics on $\mathrm{PM}_{2.5}$ concentration in South Korea have been released by the KMOE only since 2015, but recent studies indicate that the adverse effects of $\mathrm{PM}_{2.5}$ are greater than those of $\mathrm{PM}_{10}$ [35]. $\mathrm{PM}_{2.5}$ exposure has recently been found to increase the risks of not only cardiovascular and respiratory disease, but also of neurological diseases such as Parkinson's disease [36]. This highlights the need for future studies to include effects other than those classically studied with finer particles. Future research efforts could also include investigating the health impact of other air pollutants such as ozone, nitrogen dioxide, and sulfur dioxide. Lastly, we were not able to consider comorbidity, although pre-existing diseases may influence susceptibility. Further investigations should focus on 
susceptible groups and need to follow up cohorts in order to investigate the effects of air pollution on disease progression.

\section{Conclusions}

In an analysis of data from 1995 to 2014 on elderly residents of Seoul, South Korea, we confirmed the positive association between an increase in $\mathrm{PM}_{10}$ concentration and increased daily mortality. The synergism of $\mathrm{PM}_{10}$ concentration with temperature showed different patterns with different causes of death, and the shape. Our findings have clear implications for planning public health interventions and controlling emissions in the near future as temperatures increase with climate change and populations continue to age.

Author Contributions: Conceptualization, S.E.K.; methodology, S.E.K.; data curation, T.N.; formal analysis, S.E.K.; writing—original draft preparation, S.E.K.; writing—-review and editing, S.E.K., Y.H., T.N., and H.K.; supervision, S.E.K., Y.H., and H.K.; funding acquisition, S.E.K. and Y.H. All authors have read and agreed to the published version of the manuscript.

Funding: This work was supported by the Climate Change Adaptation Research Program of the National Institute for Environmental Studies of Japan and by the Basic Science Research Program through the National Research Foundation, funded by the Ministry of Education of Korea (2019R1A6A3A03031690).

Conflicts of Interest: The authors declare no conflicts of interest.

\section{References}

1. James, S.L.; Abate, D.; Abate, K.H.; Abay, S.M.; Abbafati, C.; Abbasi, N.; Abbastabar, H.; Abd-Allah, F.; Abdela, J.; Abdelalim, A.; et al. Global, regional, and national incidence, prevalence, and years lived with disability for 354 Diseases and Injuries for 195 countries and territories, 1990-2017: A systematic analysis for the Global Burden of Disease Study 2017. Lancet 2018, 392, 1789-1858. [CrossRef]

2. Jung, M.; Cho, D. The Impact of Particulate Matter on Outdoor Activity and Mental Health: A Matching Approach. Int. J. Env. Res. Public Health 2019, 16, 2893. [CrossRef]

3. Ahmed, C.; Jiang, H.; Chen, J.; Lin, Y.-H. Traffic-Related Particulate Matter and Cardiometabolic Syndrome: A Review. Atmosphere 2018, 9, 336. [CrossRef]

4. Chen, R.; Kan, H.; Chen, B.; Huang, W.; Bai, Z.; Song, G.; Pan, G. Association of particulate air pollution with daily mortality: The China air pollution and health effects study. Am. J. Epidemiol. 2012, 175, 1173-1181. [CrossRef]

5. Sunil, V.R.; Patel, K.J.; Mainelis, G.; Turpin, B.J; Ridgely, S.; Laumbach, R.J.; Kipen, H.M.; Nazarenko, Y.; Veleeparambil, M.; Gow, A.J.; et al. Pulmonary effects of inhaled diesel exhaust in aged mice. Toxicol. Appl. Pharmacol. 2009, 241, 283-293. [CrossRef] [PubMed]

6. Gomez, C.R.; Nomellini, V.; Faunce, D.E.; Kovacs, E.J. Innate immunity and aging. Exp. Gerontol. 2008, 43, 718-728. [CrossRef] [PubMed]

7. He, W.; Goodkind, D.; Kowal, P.R. An aging world: 2015-International Population Reports; U.S. Government Publishing Office; United States Census Bureau: Washington, DC, USA, 2016.

8. Bae, S.; Kwon, H.J. Current state of research on the risk of morbidity and mortality associated with air pollution in korea. Yonsei Med. J. 2019, 60, 243-256. [CrossRef] [PubMed]

9. Willers, S.M.; Jonker, M.F.; Klok, L.; Keuken, M.P.; Odink, J.; van den Elshout, S.; Sabel, C.E.; Mackenbach, J.P; Burdorf, A. High resolution exposure modelling of heat and air pollution and the impact on mortality. Environ. Int. 2016, 89, 102-109. [CrossRef] [PubMed]

10. Analitis, A.; De' Donato, F.; Scortichini, M.; Lanki, T.; Basagana, X.; Ballester, F.; Astrom, C.; Paldy, A.; Pascal, M.; Gasparrini, A.; et al. Synergistic Effects of Ambient Temperature and Air Pollution on Health in Europe: Results from the PHASE Project. Int. J. Environ. Res. Public Health 2018, 15, 1856. [CrossRef]

11. Kim, S.E.S.E.; Lim, Y.H.Y.-H.; Kim, H. Temperature modifies the association between particulate air pollution and mortality: A multi-city study in South Korea. Sci. Total Environ. 2015, 524, 376-383. [CrossRef]

12. Tian, L.; Liang, F.; Guo, Q.; Chen, S.; Xiao, S.; Wu, Z.; Jin, X.; Pan, X. The effects of interaction between particulate matter and temperature on mortality in Beijing, China. Environ. Sci. Process. Impacts 2018, 20, 395-405. [CrossRef] [PubMed] 
13. Luís Ferreira Braga, A.; Zanobetti, A.; Schwartz, J. The Lag Structure Between Particulate Air Pollution and Respiratory and Cardiovascular Deaths in 10 US Cities. J. Occup. Environ. Med. 2001, 43, 927-933. [CrossRef] [PubMed]

14. KOSIS Population Density (Population and Housing Census). Available online: http: //kosis.kr/statHtml/statHtml.do?orgId=101\&tblId=DT_1B08024\&vw_cd=MT_ZTITLE\&list_id=A1_

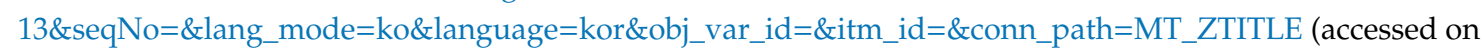
2 October 2019).

15. KOSIS Elderly population ratio. Available online: http://kosis.kr/statHtml/statHtml.do?orgId=101\&tblId= DT_1YL20631 (accessed on 2 October 2019).

16. WHO. WHO Air Quality Guidelines for Particulate Matter, Ozone, Nitrogen Dioxide and Sulfur Dioxide: Summary of Risk Assessment; WHO: Geneva, Switzerland, 2006; ISBN 9289021926.

17. Wood, S. On confidence intervals for generalized additive models based on penalized regression splines. Aust. New Zealand J. Stat. 2006, 48, 445-464. [CrossRef]

18. Son, J.Y.; Bell, M.L. The relationships between short-term exposure to particulate matter and mortality in Korea: Impact of particulate matter exposure metrics for sub-daily exposures. Environ. Res. Lett. 2013, 8.

19. Wong, C.M.; Vichit-Vadakan, N.; Kan, H.; Qian, Z.; Vajanapoom, N.; Ostro, B.; Wong, C.M.; Thach, T.Q.; Chau, P.Y.K.; Chan, K.P.; et al. Public Health and Air Pollution in Asia (PAPA): A multicity study of short-term effects of air pollution on mortality. Environ. Health Perspect. 2008, 116, 1195-1202. [CrossRef] [PubMed]

20. Ostro, B.; Chestnut, L.; Vichit-Vadakan, N.; Laixuthai, A. The impact of particulate matter on daily mortality in Bangkok, Thailand. J. Air Waste Manag. Assoc. 1999, 49, 100-107. [CrossRef] [PubMed]

21. Stafoggia, M.; Samoli, E.; Alessandrini, E.; Cadum, E.; Ostro, B.; Berti, G.; Faustini, A.; Jacquemin, B.; Linares, C.; Pascal, M.; et al. Short-term associations between fine and coarse particulate matter and hospitalizations in Southern Europe: Results from the MED-PARTICLES project. Environ. Health Perspect. 2013, 121, 1026-1033. [CrossRef]

22. Zeka, A.; Zanobetti, A.; Schwartz, J. Short term effects of particulate matter on cause specific mortality: Effects of lags and modification by city characteristics. Occup. Environ. Med. 2005, 62, 718-725. [CrossRef]

23. Kan, H.; London, S.J.; Chen, G.; Zhang, Y.; Song, G.; Zhao, N.; Jiang, L.; Chen, B. Season, sex, age, and education as modifiers of the effects of outdoor air pollution on daily mortality in Shanghai, China: The Public Health and Air Pollution in Asia (PAPA) study. Environ. Health Perspect. 2008, 116, 1183-1188. [CrossRef]

24. Yap, J.; Ng, Y.; Yeo, K.K.; Sahlén, A.; Lam, C.S.P.; Lee, V.; Ma, S. Particulate air pollution on cardiovascular mortality in the tropics: Impact on the elderly. Environ. Health A Glob. Access Sci. Source 2019, 18, 1-9. [CrossRef]

25. Yu, G.-H.; Park, S.-S.; Park, J.S.; Park, S.M.; Song, I.H.; Oh, J.; Shin, H.J.; Lee, M.D.; Lim, H.B.; Kim, H.W.; et al. Pollution Characteristics of PM2.5 Observed during Winter and Summer in Baengryeongdo and Seoul. J. Korean Soc. Atmos. Environ. 2018, 34, 38-55. [CrossRef]

26. Zanobetti, A.; Schwartz, J.; Samoli, E.; Gryparis, A.; Touloumi, G.; Peacock, J.; Anderson, R.H.; Le Tertre, A.; Bobros, J.; Celko, M.; et al. The temporal pattern of respiratory and heart disease mortality in response to air pollution. Environ. Health Perspect. 2003, 111, 1188-1193. [CrossRef] [PubMed]

27. Brook, R.D.; Rajagopalan, S.; Pope, C.A.; Brook, J.R.; Bhatnagar, A.; Diez-Roux, A.V.; Holguin, F.; Hong, Y.; Luepker, R.V.; Mittleman, M.A.; et al. Particulate matter air pollution and cardiovascular disease: An update to the scientific statement from the american heart association. Circulation 2010, 121, 2331-2378. [CrossRef] [PubMed]

28. Ostro, B.; Roth, L.; Malig, B.; Marty, M. The effects of fine particle components on respiratory hospital admissions in children. Environ. Health Perspect. 2009, 117, 475-480. [CrossRef]

29. Zelikoff, J.T.; Chen, L.C.; Cohen, M.D.; Fang, K.; Gordon, T.; Li, Y.; Nadziejko, C.; Schlesinger, R.B. Effects of inhaled ambient particulate matter on pulmonary antimicrobial immune defense. Inhal. Toxicol. 2003, 15, 131-150. [CrossRef]

30. Clougherty, J.E. A growing role for gender analysis in air pollution epidemiology. Environ. Health Perspect. 2010, 118, 167-176. [CrossRef]

31. Sara, H.; Barney, C. Department of Economic and Social Affairs, P.D. Population 2030: Demographic Challenges and Opportunities for Sustainable Development Planning; United Nations: New York, NY, USA, 2015. 
32. Statistics of Korea Population Projections for Korea. Available online: http://kosis.kr/statHtml/statHtml. do?orgId=101\&tblId=DT_1BPA401\&vw_cd=MT_ZTITLE\&list_id=A41_10\&seqNo=\&lang_mode=ko\& language=kor\&obj_var_id=\&itm_id=\&conn_path=MT_ZTITLE (accessed on 2 October 2019).

33. Laumbach, R.; Meng, Q.; Kipen, H. What can individuals do to reduce personal health risks from air pollution? J. Thorac. Dis. 2015, 7, 96-107.

34. Sharma, A.P.; Kim, K.H.; Ahn, J.W.; Shon, Z.H.; Sohn, J.R.; Lee, J.H.; Ma, C.J.; Brown, R.J.C. Ambient particulate matter (PM10) concentrations in major urban areas of Korea during 1996-2010. Atmos. Pollut. Res. 2014, 5, 161-169. [CrossRef]

35. Zhao, Y.; Cheng, Z.; Lu, Y.; Chang, X.; Chan, C.; Bai, Y.; Zhang, Y.; Cheng, N. PM10 and PM2.5 particles as main air pollutants contributing to rising risks of coronary heart disease: A systematic review. Environ. Technol. Rev. 2017, 6, 174-185. [CrossRef]

36. Lee, H.; Myung, W.; Kim, D.K.; Kim, S.E.; Kim, C.T.; Kim, H. Short-term air pollution exposure aggravates Parkinson's disease in a population-based cohort. Sci. Rep. 2017, 7, 44741. [CrossRef]

(C) 2019 by the authors. Licensee MDPI, Basel, Switzerland. This article is an open access article distributed under the terms and conditions of the Creative Commons Attribution (CC BY) license (http://creativecommons.org/licenses/by/4.0/). 